\title{
Strategic Appraisal of Interdependent Infrastructure Provision: A Case Study From the Thames Hub
}

\author{
Kate Younga \\ Jim Halla
}

\begin{abstract}
Evaluation of potential infrastructure projects varies from straightforward financial assessment, to explicit methods requiring multi-criteria valuation and uncertainty analysis. All, however, are siloed to their own sector and in many cases the stand-alone project under consideration, ignoring the growing interdependence between the sectors. Here we develop a long-term multi-sector, multi-attribute decision analysis, demonstrated through a case study on the Thames Hub proposal. Uncertainty is assessed through sensitivity analysis, provisioning time-dependency analysis and an adapted real options analysis, to produce bounded valuation of decision pathways. Further consideration of spatial feedbacks is then reviewed through a land-use transport model. The results are brought together to demonstrate a strategic, integrated infrastructure assessment methodology, focused on delivering long-term resilience despite uncertainty.
\end{abstract}

Key words: Infrastructure systems; Interdependency; Flexibility; Multicriteria analysis; Decision support; Real options

\section{Introduction}

The five lifeline infrastructures (communications, energy, transport, water and waste) have vast impacts on the populous' wellbeing, the environment and the financial welfare of the country. Yet, while it is acknowledged these infrastructures function as a system of systems, appraisal of new infrastructure provision is made at the sector, or individual asset level. This reduction of the system complexity significantly limits the validity of results ${ }^{1}$, (i) ignoring macro-scale impacts, such as economic growth, which only manifest where systems complement each other ${ }^{2,3}$; (ii) concealing resource constraints, where decisions make other options impossible to realise or invalidate the business case behind them; and (iii) ignoring direct (and indirect) demand on other sectors.

Errors are further extrapolated due to the long term nature and time dependency of infrastructure investments. Infrastructure benefits are highly dependent on the performance of the other sectors, with impacts on those possible and the likelihood of realisation. Furthermore, implementing options will put constraints on the development of the other sectors. Sector based analysis ignores system constraints imposed on concurrent and future provisioning and often overlooks the time dependency of provisioning on other sector

a Environmental Change Institute, Oxford University Centre for the Environment, Oxford, OX1 3QY, UK http://dx.doi.org/10.14453/isngi2013.proc.52 
benefits. By inclusion of dependency we more fully assess the interdependency risk and, by consideration of this, can explore more flexible decision pathways, using methods such as real options analysis (ROA). We therefore reduce the risk of investments, particularly at the concept design stage, where assumptions will be severely uncertain.

The aims of this work are: (i) to provide a framework capable of appraising multiple sector networks, capturing system impacts and allowing for different sequencing of provisioning options throughout time to make up a functional interacting system; and (ii) to provide a method to view these feasible combinations and their multiple benefits to support the process of decision making from a policy maker's perspective. This paper first sets out current appraisal practices within the sectors (section 2), before proposing a framework to extend methods to include interdependency and future flexibility in section 3 . The framework is tested against a case study on the 'Thames Hub' vision in section 4, with conclusions drawn in section 5 .

\section{Current Appraisal Methods}

Appraisal processes aim to deduce solutions with the maximum utility for a given level of resource. In the case of private infrastructure investors, this resource may simply be monetary, through the use of straightforward financial assessment. However, as many infrastructure assets necessitate partial public funding, regulatory approval, and/or planning permission, further multicriteria analysis (MCA) or uncertainty analysis is often required.

Both the water and transport sectors in the UK have structured frameworks, based on cost benefit analysis (CBA) and MCA. The Department for Transport's 'WebTAG' methodology, for example, is thought to be some of the most comprehensive transport appraisal guidance in the world ${ }^{4}$, and forms the basis of the World Bank's Transport Appraisal Toolkit. The timeframe (60 years), however, is still substantially shorter than that of the investments ${ }^{5}$ and the assessment is almost entirely sector specific (energy demand is considered for tax and emission purposes). While both water and transport sectors consider multiple criteria, the methods are not easily comparable, leading to potential underfunding in some sectors ${ }^{6}$. Both sectors accept there is uncertainty in future system state conditions and use uncertainty analysis (and scenario analysis in the case of the water sector) to explore this. Yet no account is made of constraints placed on future provisioning, or the options these decisions hold for adaptation to changing conditions.

While the analysis outputs are specified to ensure consistency across proposals, they are still highly complex. For policy makers to move beyond their historical satisficing, methods must be more carefully communicated, with trade-offs and timeframes available for further exploration and future review against increasing levels of information ${ }^{7}$.

\section{Inclusion of Flexibility and Interdependency}

Our framework builds on the existing sector specific MCAs. The framework is depicted in Figure 1 and can be summarised in four stages:

- Strategic review: Identification of cross-sectoral opportunities and necessary generic performance metrics;

- Pathway creation: Generation of options and application of interdependencies; 
- Analysis: MCA and sensitivity analysis brought together in an option analysis and pairwise comparison with a cross-sector informed do minimum; and

- Review: Testing of assumptions, objectives and the decision pathway chosen as uncertainty diminishes.

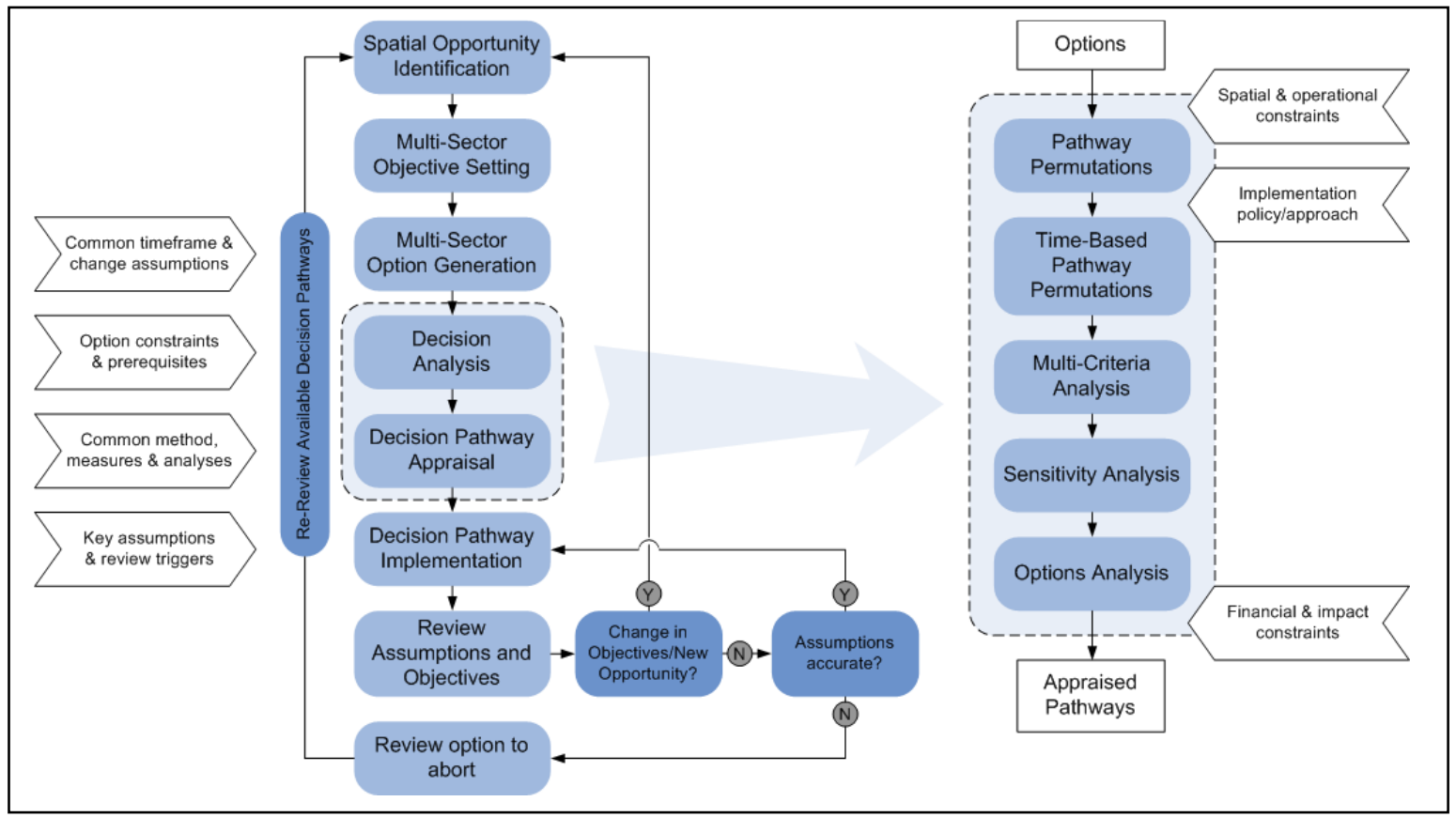

Figure 1. Proposed multi-sector appraisal framework.

We propose a regional focus, with strategic opportunities and challenges identified spatially rather than sectorally. Performance metrics and methods are generic, developed to depict the realisation of cross-sector opportunities and high level regulatory requirements, but also to explicitly record the cross-sector demand requirements. Metrics are set to encompass multiple stakeholder viewpoints under four subject headings: environmental, service, social and economic/financial.

The analysis takes a long-term (100 year), severe uncertainty decision approach, drawing on the literature of robust decision making, using an adapted ROA. While real option assumptions have limited applicability for infrastructure investments ${ }^{8.9} ;$, these can be overcome, with ROA having been successfully explored in a number of single sector contexts $10,11,12$. However, its use in real-world infrastructure decision making is limited to date ${ }^{13}$. Here, we apply the pathway uncertainty analysis of ROA through uncertainty analysis of key system state variables and time dependency analysis of implementation. However, recognising the severe uncertainty at conceptual design stages, we combine these in a minmax decision pathway analysis, rather than compiling defined probability distributions.

It is recognised that some system state variables are coupled to the infrastructure investments made.

To initially simplify the analysis, these variables (population, carbon price, sea level rise and fossil fuel prices) are treated as exogenous; however key assumptions are identified (population and carbon price) and explored through uncertainty analysis. Land Use Transport 
Modelling can be used to further explore the interactions between the investments and the demand for their services. Interdependency is incorporated by explicitly recording the crosssector demand and through consideration of constraints during the path dependency analysis. Here potential pathways are considered against the four interdependencies in Table 1. Spatial and operational constraints are considered during the 'pathway creation' stage, with financial and impact constraints applied through thresholds after the options analysis ('analysis' stage).

Table 1. Topology of interdependencies.

\begin{tabular}{|l|l|}
\hline Interdependence & Resource Limitation \\
\hline Spatial & Geographical location \\
\hline Operational & Functional resource such as water, electricity, or skills \\
\hline Financial & Funding available or revenue realized \\
\hline Impact & Outputs such as emissions, noise or habitat loss \\
\hline
\end{tabular}

Finally, feasible pathways are displayed as a decision tree with min-max outputs and uncertainty levels collated under the four subject headings (see Figure 2). The output range is visible to the decision maker along with how this changes with each future decision taken. It highlights which constituent infrastructure options are key to the delivery of benefits, how these build up together across sectors and how the benefits are affected by the uncertainty of system state variables. It therefore recognises routes of high uncertainty and promotes the tracking key assumptions and identification of 'trigger points' where a change in direction should be considered.

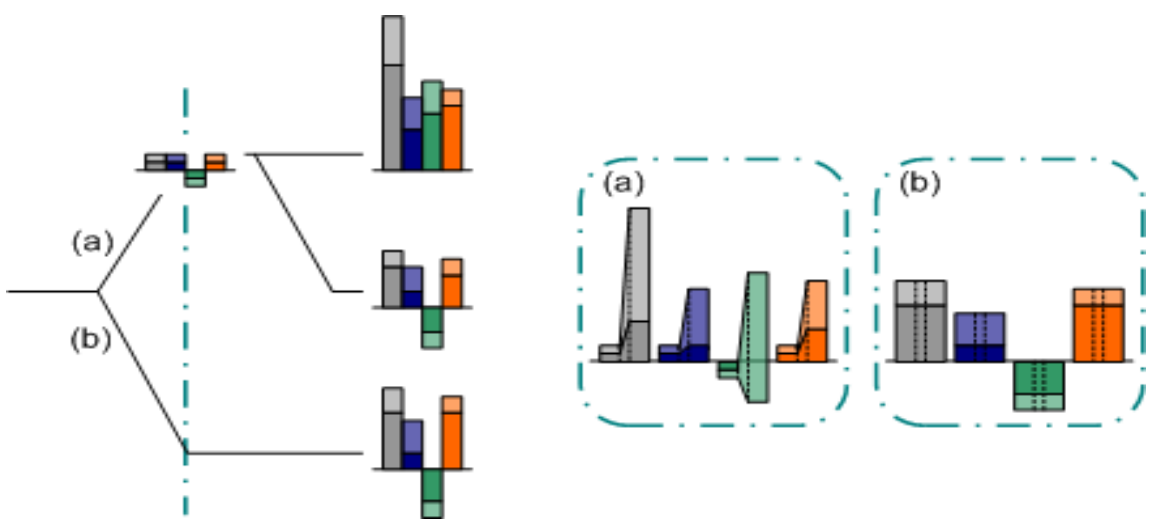

Figure 2. Pathway flexibility analysis.

\section{Case Study on the 'Thames Hub' Vision}

The framework has been applied to the 'Thames Hub' vision, a proposal for the development of an integrated infrastructure hub in the Thames Estuary, South East England. It includes a new hub airport, high speed and commuter rail lines orbiting London, a new Thames flood barrier and a tidal energy barrage. It therefore directly includes water (flood), transport and energy sectors, with implications for the communications, water (provisioning) and waste sectors. The time dependence of the element impacts and their interdependence is illustrated for rail in

Figure 3. 


Time $\mathrm{N}$ Ime (N+1)

Figure 3. Illustrative interdependence and time dependence of rail and airport impacts.

Sector performance metrics, were reviewed for the primary infrastructures and developed into 15 cross-sector metrics under the four subject headings. These are displayed along with an initial assessment of impact for a single pathway in

Figure 4. A full MCA of all pathways under different policy approaches is currently underway.

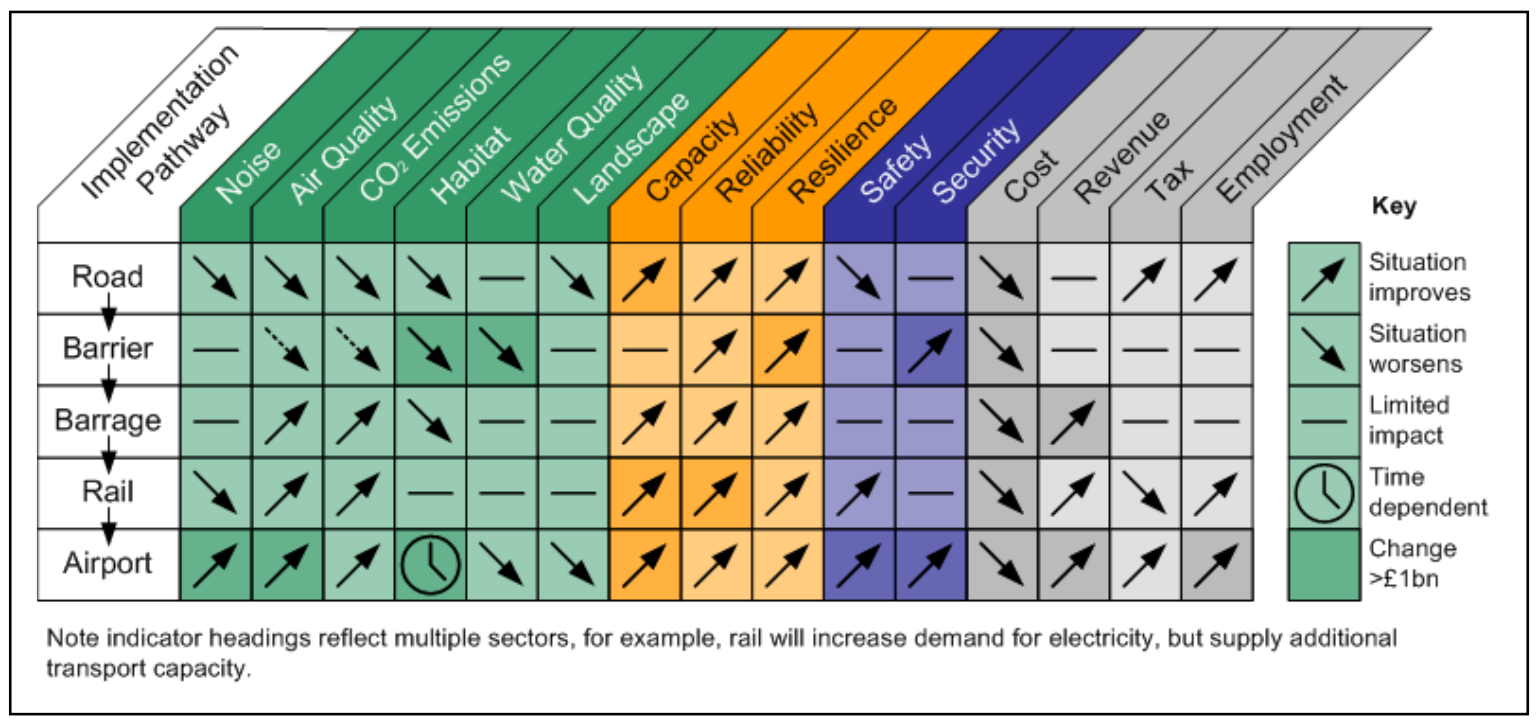

Figure 4. Single pathway MCA.

\section{Conclusion}

We argue that interdependency of infrastructure networks needs to be considered during appraisal to more fully capture the impacts and benefits realised and the risk profile of infrastructure investments. We posit that resilient choices are possible despite high levels of uncertainty, through the incorporation of these interdependencies within and adapted ROA 
and the ongoing review of choices. We have proposed such a framework, that is capable of devising possible cross-sector infrastructure option combinations ('pathways'), analysing the time sequencing of their implementation and capturing the uncertainty of their impacts through sensitivity analysis, an adapted real options analysis and exploration through Land Use Transport Modelling. We have also proposed how this can feed into a decision support visualisation that displays the feasible combinations, their multiple benefits and how these vary through pathway 'families', to support decision making and ongoing review. In particular it enables understanding of the implications of when the investments are made, both due to the future uncertainty and through understanding how implementation policies affect the total benefits achieved. Further we have provided a consistent cross-sector methodology with generic performance measures that allows prioritisation across sectors where resources are constrained. The methodology has been applied to a case study on the 'Thames Hub' vision demonstrating the presence of system benefits and temporal characteristics that would be ignored through traditional valuation methods and the potential for development of cross sector performance metrics.

The framework is strategically focused assuming initiation at the concept design stage and the regional spatial scale. It is therefore limited by the information available at this stage and the amalgamation of data within this space. Further analysis of lower spatial and temporal scales would provide useful information on the interdependencies of infrastructure networks and is being conducted as part of the Infrastructure Transitions Research Consortium (ITRC), but is beyond the scope of this study. Future work will focus on further development of the case study option valuation and additional analysis of system state conditions, through use of the ARCADIA Land-Use Transport Model.

\section{References}

${ }^{1}$ Rinaldi, S. M., "Modeling and simulating critical infrastructures and their interdependencies", Proceedings of the 37th Annual Hawaii International Conference on System Sciences,Hawaii, USA: Hilton Waikoloa Village, 2004, pp.873 -880.

${ }^{2}$ Banister, D., and Berechman, J., Transport investment and economic development (Taylor and Francis e-Library ed.). London: UCL Press, 2003.

${ }^{3}$ Beuthe, M., "Transport evaluation methods: From cost-benefit analysis to multicriteria analysis and the decision framework", in L. Giorgi, A. D. Pearman and Interdisciplinary Centre for Comparative Research in the Social Sciences (Editors), Project and policy evaluation in transport, Aldershot: Ashgate, 2002, pp. 209-241.

${ }^{4}$ Sumner, R., Audit and development of RAILMOD, prepared for the European Investment Bank. Client Report: Halcrow, 2011.

${ }^{5} \mathrm{OECD}$, Improving the practice of transport project appraisal, [Electronic version] International Transport Forum Round Tables, (No. 149), OECD Publishing, 2011.

${ }^{6}$ Mackie, P., "Cost-benefit analysis in transport: A UK perspective", OECD International Transport Forum, Discussion Paper No 2010-16, 2010.

${ }^{7}$ Hickman, R., Saxena, S., Banister, D., and Ashiru, O., "Examining transport futures with scenario analysis and MCA", Transportation Research Part A: Policy and Practice, Vol. 46, No. 3, 2012, pp. 560-575. http://dx.doi.org/10.1016/j.tra.2011.11.006

${ }^{8}$ Copeland, T., and Tufano, P., "A real-world way to manage real options", Harvard Business Review, Vol. 82, No. 3, 2004, pp. 90-99.

${ }^{9}$ Krüger, N. A., "To kill a real option - Incomplete contracts, real options and PPP”, Transportation Research Part A: Policy and Practice, Vol. 46, No. 8, 2012, pp. 13591371. http://dx.doi.org/10.1016/j.tra.2012.04.009 
${ }^{10}$ Ashuri, B., Lu, J., and Hamed, K., “A real options framework to evaluate investments in toll road projects delivered under the two-phase development strategy", Built

Environment Project and Asset Management, Vol. 1, No. 1, 2011, pp. 14-31. http://dx.doi.org/10.1108/20441241111143759

${ }^{11}$ Fernandes, B., Cunha, J., and Ferreira, P., "The use of real options approach in energy sector investments", Renewable and Sustainable Energy Reviews, Vol. 15, No. 9, 2011, pp. 4491-4497. http://dx.doi.org/10.1016/j.rser.2011.07.102

${ }^{12}$ Guo, X., and Jiang, T., "Study on IT infrastructure investment appraisal based on realoption theory", Proceedings of the 2010 International Conference on Challenges in Environmental Science and Computer Engineering, Wuhan, China, Vol. 2, 2010, pp. 158-161.

${ }^{13}$ Herder, P. M., De Joode, J., Ligtvoet, A., Schenk, S., and Taneja, P., "Buying real options Valuing uncertainty in infrastructure planning”, Futures, Special Issue: Flexible Infrastructures, Vol. 43, No. 9, 2011, pp. 961-969. 